\title{
CANTOS Y CANTORES CONSTRUCTORES DE IDENTIDADES EN FRAY MARCOS (URUGUAY)
}

\author{
Juan Scuro ${ }^{1}$
}

\section{Introducción}

En este artículo se exponen algunas reflexiones a partir de un acercamiento etnográfico a la localidad de Fray Marcos (población de unos tres mil habitantes ubicada en el sudeste del departamento de Florida, Uruguay) y a los sujetos que allí construyen un modo de vida determinado por ciertas características del pueblo. El vínculo que los pobladores desarrollan con la historia del pueblo, la memoria que se mantiene en relación a ciertos sujetos míticos de la zona y otros elementos significativos, determinan un conjunto de variables que particularizan y definen (de alguna manera) a Fray Marcos. El mayor interés esta puesto en el abordaje de los elementos vinculados a la producción musical como espacio de expresión y comunicación. En estas performances artísticas, los músicos y espectadores son creadores y recreadores de vínculos con un mundo de representaciones de lo identitario.

Los relatos transmitidos de forma oral a lo largo de la historia van conformando una identidad del pueblo a partir de elementos de diferenciación con otros, tal es el caso del recuerdo de personajes históricos como Néstor Feria o Martín Aquino. En el caso del primero, es sabido que nació en el pueblo vecino Bolívar pero se desarrolló en Fray Marcos, el segundo, "el último matrero", es causa de diferentes relatos relacionados a su recorrido por aquellas zonas. Como parte de "lo que se respira" en Fray Marcos, estas historias también forman parte del canto del lugar y constituyen también el acervo de los pobladores de la zona. Lejos de intentar una aproximación histórica al devenir de Fray Marcos, encontré significativo el hecho de las diversas apropiaciones de las temporalidades posibles del pueblo.

Ese "hacer el mundo nombrándolo" del que habla Bourdieu (Bourdieu, 2001), es el que construye los distintos Fray Marcos, los múltiples orígenes posibles que habitan en las realidades construidas por los pobladores del lugar. El abanico de representaciones diversas entorno al pueblo y su devenir crea una dinámica propia de lucha por un poder simbólico constituyente del lugar que alberga distintos sujetos. No esta ausente en Fray Marcos, como es lógico suponer, la superposición de memorias y

\footnotetext{
${ }^{1}$ Universidad de la República, Uruguay.
} 
representaciones que conviven conflictiva y armónicamente. Se trata de sujetos y de prácticas, de tradiciones y memorias constructoras de identidades. Se hace un trabajo de antropología y por lo tanto, una invitación a la reflexión acerca de otras reflexividades.

\section{Fray Marcos}

Uno de los primeros pobladores de la zona, como cuenta Celestino (habitante del pueblo), fue Ramón Latorre que, según él, “era de la gente de Oribe ”. Ramón Latorre fue un hacendado de mediados del siglo XIX que habitó la región de la denominada "Estancia de la Caballada del Rey", campos situados en las costas del Río Santa Lucía. Celestino cuenta que su familia, la familia Martínez, está en la zona desde 1850, incluso su bisabuelo Agustín Martínez Viademonte vivió en la estancia de Ramón Latorre. Agustín había venido desde Asturias y pudo comprar doscientas hectáreas en 1882, campo que hoy es lindero al cementerio de Fray Marcos donde descansa, entre otros, su padre.

Según cuenta Celestino, Ramón Latorre habría entregado parte de sus tierras para que se pudiera trazar la vía del ferrocarril a cambio de que la estación llevara su nombre. El avance del capitalismo y las inversiones inglesas hacían que se comenzara a forjar un nuevo territorio de explotación ganadera y lanar. El ferrocarril constituía una herramienta fundamental en ese momento y debían trazarse los recorridos a conveniencia de los explotadores de los recursos. En este caso, la estación de ferrocarril del lugar se inaugura en 1888, denominándose, como cuenta Celestino, Estación Latorre. "Las cartas iban dirigidas a Estación Latorre pero la zona se decía Paso de Fray Marcos porque se ahogó un fraile llamado Marcos", cuenta Celestino. La muerte del fraile Marcos habría dado lugar al nombre del paso, es decir, el cruce del río donde habría muerto el fraile, lo que hizo que la zona se denominara así pero la estación seguía llamándose Latorre desde 1888 y hasta 1920, año en que murió Ramón Latorre y la estación pasó a llamarse Estación Fray Marcos.

Para Eduardo Tapié, médico del pueblo que vive allí desde 1985, "lo del fraile ahogado es la versión 'romántica', el nombre Fray Marcos los pusieron los ingleses porque la compañía de trenes había puesto un ramal en Texas (Arizona)"; "El fraile Marcos es producto del folklore”. Así parece que la misma compañía de trenes que realizó las obras en Uruguay hizo ciertos ramales de las líneas ferroviarias de Estados

\footnotetext{
${ }^{2}$ Segundo presidente constitucional del Uruguay (1935-1938), sucesor de Rivera. Fundador del Partido Nacional.
} 
Unidos, línea en la que, según Eduardo, existe una estación Fray Marcos precedida por otra llamada Chamizo. En el recorrido de la línea uruguaya, la estación que precede a la de Fray Marcos es la de Chamizo. La abuela de Tapié era Latorre, apellido que según Eduardo esta presente en el lugar desde el siglo XVII. Parece ser que Oribe habría dado la propiedad de las tierras a Latorre.

Resulta interesante observar el comienzo de lo que será una constante polifonía que emana de las distintas narrativas. Esta múltiple aprehensión discursiva evidencia un entramado de construcciones identitarias conflictivas. Convive esa "lucha por la definición de la identidad" (Bourdieu, 2001:88) evidenciada al "incluir en lo real la representación de lo real" que viene a derribar la dicotomía realidad-ficción. El giro de Ricoeur en alusión a esta relación entre realidad y ficción da paso a las distintas posibilidades de aprehensión de lo tradicional. Al dotar a la ficción de una cierta modalidad referencial otorgamos a esta la posibilidad de construir un sistema simbólico que contribuye a la configuración de la realidad (Ricoeur, 2006:20).

\section{Los tiempos que dan origen a Martín Aquino}

Desde el comienzo del gobierno de Manuel Oribe (1835-1838) se lo vinculó a éste con la campaña y el medio rural. Él y sus seguidores conformaron el Partido Nacional con un fuerte sentimiento de defensa de la nacionalidad contra intervenciones extranjeras (Nahum, 2003). Esta hostilidad se manifestó en la expulsión por parte de Oribe de los propietarios europeos de campos en el interior del país. Como sostiene Benjamín Nahum, la temprana vinculación de "los blancos" ${ }^{3}$ " al interior del país y su campaña fueron produciendo una fuerte identificación de estos con el sentimiento nacional, con el orden y la autoridad (Nahum, 2003).

A partir de la segunda mitad del siglo XIX el país vive un largo proceso de unificación y pacificación tras varias décadas de desencuentros y arrebatos del poder por parte de distintos agentes tanto nacionales como extranjeros. El fin de la denominada Guerra Grande supuso un nuevo rumbo para el Uruguay incipiente que lentamente comenzaba a poblarse tanto en Montevideo como en el interior. En la década de 1850 el país vivió un gran crecimiento demográfico y se destaca la presencia de extranjeros en los censos. Sin embargo, el principal punto de concentración de la

\footnotetext{
${ }^{3}$ Forma en que se denomina a quienes adhieren al Partido Nacional
} 
población seguía siendo Montevideo y el interior del país continuaba siendo bastante despoblado (Nahum, 2003).

El Departamento de Florida (donde se ubica Fray Marcos) tiene sus límites políticos actuales desde 1856, luego que el entonces Departamento de San José fuera dividido al medio. En 1860 Florida contaba con doce mil ciento setenta habitantes de los cuales más de un diez por ciento eran de origen extranjero (Nahum, 2003). No solo se incrementaba la población de seres humanos sino también la ganadera, especialmente la ovina. La llamada revolución del lanar introdujo grandes cambio y obligó a una modernización del medio rural importante. Este hecho significó, según Nahum, un reforzamiento económico y político por parte de los estancieros que obligaron a conducir al medio a un régimen capitalista de explotación de los recursos, impulsado fuertemente por las inversiones extranjeras (principalmente británicas) (Nahum, 2003). Al día de hoy la zona de Fray Marcos es responsable de la exportación de grandes cantidades de lana fina, de buena calidad, asegurando de esta manera un caudal importante de mano de obra. La sedentarización que este nuevo recurso exigía contribuyó a la necesidad de alambrar los campos al mismo tiempo que el modelo capitalista de explotación imponía imperiosamente la creación de vías de comunicación adecuadas. Todos estos elementos comienzan a acotar el poder de los caudillos. La mayor facilidad para el traslado de los ejércitos nacionales, el alambrado, comienza a dificultar las tareas de estos sujetos. El final de este proceso de reducción de poder culmina con la derrota de Aparicio Saravia en 1904. El legado de esta tradición caudillezca permanece en Martín Aquino quién, aún entrado el siglo XX, continúa con prácticas de rebeldía hacia la autoridad. Así es como bajo un nuevo orden social, Martín Aquino se convierte en el último matrero de la patria. Su época es la de los comienzos de Fray Marcos como población, ya que la explotación de recursos obligaba a las empresas ferroviarias a trazar sus recorridos por el lugar que hoy ocupa Fray Marcos. "Hacia 1880, cuando terminaba el gobierno de Latorre, el ferrocarril llegaba a Durazno atravesando el río Yí con un largo puente y a San José. En todo el país había 287 Km de vías férreas, que habrían de extenderse mucho más bajo el gobierno siguiente de Santos" (Nahum, 2003:184).

A partir de 1888, con la construcción de la vía férrea que iba hasta Nico Pérez se establece una población en los campos de Ramón Latorre a quién el Gobierno de Oribe le había reconocido en propiedad en 1836. Se trataba de dos estancias entre los ríos Chamizo y Santa Lucía Grande que abarcarían un total de unas cuatro mil hectáreas 
(Maqueira, 2006). Así surgió su nombre como Pueblo Latorre (o Estación Latorre) por donde pasó un primer tren el primero de Setiembre de 1891. La estación construida en aquella época puede verse hoy bastante deteriorada pero existen algunos proyectos para utilizarla en algún emprendimiento cultural que esta surgiendo en el pueblo. Los primeros pobladores del lugar provenían del Paso Fray Marcos sobre el río Santa Lucía donde se desarrollo la batalla de Fray Marcos en 1904 ente las divisas blanca y colorada (Maqueira, 2006). Se trató de un enfrentamiento entre los revolucionarios comandados por Aparicio Saravia y las fuerzas gubernistas conducidas por Justino Muniz.

\section{Martín Aquino y el mito}

De lo que no hay duda es que por Fray Marcos pasó Martín Aquino, el último matrero. Ser matrero es ser rebelde, así se construye al personaje en Fray Marcos; es ser un hombre "de a caballo y sin fronteras" como se titula un programa de radio del pueblo y también un disco de uno de los músicos de allí. Pero también es el lugar de Néstor Feria, orgullo de unos cuantos en Fray Marcos. Estos fueron los primeros nombres que escuché en cuanto estuve allí, es como si no se pudiera estar en aquel sitio sin "respirar" el aire del cantor y del matrero.

En 1889 nace en Tala un personaje que dará mucho que hablar y generará unas cuantas revueltas con la ley. Martín Aquino se convierte en matrero recorriendo los campos del Uruguay, llevando ganado de un lado a otro y trabajando para distintos patrones dueños de estancias. Al comenzar a indagar acerca del recorrido de Martín Aquino me percaté de que estaba frente a una gran construcción polisemica de un trayecto transitado por un individuo a mitad de camino entre lo natural y lo sobrenatural, es decir, ante un mito. Como sostiene Levi-Strauss, "en un mito todo puede suceder; parecería que la sucesión de los acontecimientos no esta subordinada a ninguna regla de lógica o de continuidad" (Levi-Strauss, 1987:230). Para derribar de toda hegemonía historicista que intente colocar al héroe en un único lugar inamovible es que debemos recordar que, como dice Ricoeur, "La reconstrucción del pasado (...) es obra de la imaginación" (Ricoeur, 2006:21). Esto constituye una orbita delimitante de una presentación (traer al presente) de un conjunto de narraciones que construyen un personaje vivo como Martín Aquino. Irene Madfes señala, en su trabajo realizado en torno a la transmisión oral de las peripecias de Martín Aquino, que: 
testimonio (...) la tradición oral retoma los propósitos de otro (...) que forma parte de la cadena de resignificación de la historia de Aquino. Al igual que todo bien de significación, la historia del matrero es difundida, adaptada y resignificada según los agentes de la transmisión (Madfes, 1996:41).

Siguiendo a Roland Barthes concluimos que:

Si el mito es un habla, todo lo que justifique un discurso puede ser mito. El mito no se define por el objeto de su mensaje sino por la forma en que se lo profiere: sus límites son formales, no sustanciales. ¿Entonces, todo puede ser un mito? Si, yo creo que sí, porque el universo es infinitamente sugestivo. Cada objeto del mundo puede pasar de una existencia cerrada, muda, a un estado oral, abierto a la apropiación de la sociedad, pues ninguna ley, natural o no, impide hablar de las cosas (Barthes, 2005:199).

El hecho de una temprana vinculación con el medio rural machista decimonónico genera en un peón o tropero una vasta experiencia y conocimiento del campo en todas sus dimensiones. La vida rural del Uruguay del militarismo y décadas siguientes al gobierno del Coronel Lorenzo Latorre (1876-1880) hacían de la vida rural toda una "aventura" que obligaba a la gente de campo a hacerse a un modo de vida particular, caracterizado por cierto "desorden" como le gustaba ver a la clase hegemónica insistente en la instauración de un nuevo orden que abriera las puertas al capitalismo (Nahum, 2003). Ese caos del comienzo remite a un tiempo originario donde es posible el surgimiento del mito proclamando el orden primordial (Balandier, 1993). El tiempo del comienzo, el tiempo fuera del tiempo del que no es fácil obtener certezas es un tiempo en el que todo debe ser creado. Como sostiene Balandier, "el relato mítico, una vez establecido, requiere una perennidad y no varía realmente sino manteniendo sus apariencias, su forma; se inscribe en una tradición, echa raíces...” (Balandier, 1993:17).

Martín Aquino fue un hombre de campo, un hombre que se hizo fuerte y temido pero también admirado por su rebeldía y coraje. La fuerte impronta militar característica de aquellos tiempos obligaba a permanecer huyendo a quienes eran buscados por algún delito. Cuando sucedían encuentros entre policías y fugitivos generalmente tenían desenlaces violentos que podían terminar con la vida de alguno de los involucrados. Tras sus inicios fuera de la ley, Martín Aquino permaneció algún tiempo en la frontera donde "la violencia era una condición endémica de la vida rural...en el siglo XIX" (Chasteen, 2001:114). La partida de nacimiento de Martín Aquino da cuenta de su llegada al mundo en la localidad del Tala, el diecinueve de Noviembre de 1889.

En todas las aproximaciones a la figura de Martín Aquino existen discrepancias entorno a su vida y sus hábitos. Su origen es discutido, su lugar de nacimiento también, sus primeros vínculos y su afinidad al partido Colorado o Nacional también es 
discutida. Algo caracteriza a Aquino y es que genera una multiplicidad de relatos diferentes. Es aquí donde entra en juego nuestro mayor interés antropológico. Se trata de un pasado colectivo elaborado en el marco de una tradición que, como sostiene Balandier, se convierte en fuente de legitimidad (Balandier, 1999).

\section{Néstor Feria}

El 26 de Setiembre se recuerda la muerte de Néstor Feria con una gran jornada de diversas actividades. La celebración siempre se lleva a cabo el Domingo más próximo a la fecha y convoca a muchas personas del pueblo y la zona además de personalidades del ámbito político. Durante toda la semana que precedía a este Domingo permanecí en Fray Marcos mientras se notaba cierto aire de "preparativos" para el Domingo. Las tres radios comunitarias del pueblo anunciaban el programa que comenzaba por la mañana con un encuentro de las distintas sociedades nativistas en la plaza Néstor Feria. Aquel evento involucraba a todo el pueblo. Involucraba realmente a todo el pueblo porque el programa a seguir consistía en lo siguiente: desde tempranas horas de la mañana comenzaron a llegar desde distintos puntos de la zona las caballerías de las sociedades nativistas. Participaron una docena de sociedades aproximadamente lo que da un número bastante considerable de caballos y jinetes en el pueblo. Todos se concentraron en el ruedo donde se iba a desarrollar la fiesta que esta ubicado en un extremo del pueblo. A las diez de la mañana ya estaban todos dispuestos en fila para dar comienzo a la jornada frente a la placa que homenajea a Néstor Feria en una plaza ubicada en el centro del pueblo. Allí habló el organizador de la jornada y en esta oportunidad anfitrión, Pedro Torres, presidente de la Sociedad Nativista Néstor Feria.

El acto de homenaje seguiría su curso con la ida en "caravana" hasta el cementerio de Fray Marcos (ubicado en el otro extremo del pueblo) donde el intendente de Florida dijera unas palabras frente al panteón donde, desde 1988, descansan los restos del cantor. Néstor Feria murió en 1949 en Argentina pero sus restos fueron devueltos a Fray Marcos en 1988 al cumplirse el centenario del pueblo. De allí, nuevamente a la plaza central para luego dirigirse todos al ruedo principal donde se desarrollarían distintas actividades. Un gran asado estaba pronto para todos los comensales, mucho humo, vino, caballos y unos cuantos facones deambulaban por ahí mientras en el escenario se ajustaban algunos detalles para que comenzara una larga jornada de canto. Varias mesas dispuestas en fila hacían de aquello un gran almuerzo familiar, mas alejados entre las sombras de los árboles se echaban a descansar y a comer 
unos cuantos agrupados cerca de los caballos de cada sociedad criolla. Para la tarde estaba previsto que desfilaran por el escenario unos cuantos cantores mientras, de a intervalos, se realizaban algunas pruebas a caballo como carreras cortas, pruebas de rienda y otras demostraciones de las destrezas de los jinetes.

Aquel día era una fiesta para unos cuantos en el pueblo, Juvenal Martínez estaba muy entusiasmado desde temprano. Juvenal es payador y tocaba esa tarde pero también estuvo transmitiendo toda la jornada para una de las radios locales. También tocaría Walter Martínez y muchos otros invitados de otros lugares. En esos días le pregunté a Jorge Ramos si el tocaría el Domingo a lo que me respondió: no, yo no toco porque no me invitaron. Enseguida noté cierto descontento en Jorge que le hacía tener un grado de rechazo a lo que pasaría el Domingo. Jorge dirige otra de las radios del pueblo y le pregunté si también transmitiría toda la jornada pero me dijo que solo iba a transmitir la parte "oficial" de los discursos y nada más, ni se iba a aparecer por el ruedo. La radio de Jorge intenta transmitir música variada, de todo tipo de género desde el canto popular y el folklore hasta metal pesado pasando por lo tropical y otros géneros. Jorge y sus hermanos tocaban hace mucho tiempo con Walter Martínez en un grupo que se llamaba "Calle" pero después se separaron y ahora se juntan con distintas personas para tocar pero siempre se mantienen los tres hermanos. Conversando con Jorge, el me decía que entiende que hay varias "líneas" de canto. Una es la más "terruñera" que hace "folklore de raíz", son los payadores y los recitadores. Después esta el folklore "a secas" que es la milonga y la samba y por otro lado podría estar el canto popular que es más o menos lo que ellos hacen.

\section{De las prácticas musicales}

Según Carvalho existe en el folklore una "estética natural" donde intervienen pocos recursos para lograr la performance (Carvalho, 1999). En este sentido, la estética "natural" libre de agregados orbitantes posibilita un acercamiento con el público de forma "más improvisada" o "libre" ya que no depende en tan gran medida de otros aspectos como los presentes en los megashows dependientes de alta tecnología (Carvalho, 1999). En estas estéticas modernas a las que se refiere Carvalho, características de los megashows, existe un gran distanciamiento entre el artista y el público. La misma comunicación que es capaz de generar una gran emoción en el público al punto de hacer llorar a los escuchas se puede truncar en caso que no se establezcan las condiciones necesarias para la correcta transmisión de lo que se quiere 
comunicar. Así, se pueden generar encuentros en los que la función musical, la performance, adquiere un estatus de mero acompañamiento dentro del contexto discursivo. Es el caso de generar una muestra de lo tradicional en un contexto que no accede al núcleo comunicativo.

A Claudio, un habitante de Fray Marcos que hace canto popular, lo invitan de vez en cuando a tocar sus canciones en una reconocida estancia turística.

Un buen currito que tengo es ir a tocar a.... A veces voy acompañado y sino voy solo, como son todos gringos me divierto solo; nadie me entiende nada entonces hago cualquier cosa y me divierto solo.

Tanto es válido el comentario de Claudio sobre su actuación para turistas donde aparentemente (a pesar de divertirse) no puede comunicar lo suyo como al mismo tiempo convive la posibilidad de hacer llorar a quien asiste a un espectáculo musical bajo otras condiciones. Claudio se refiere a Carlos cuando recita diciendo que "Carlos te hace llorar, cuando se pone a recitar te deja llorando". Carlos se siente orgulloso y emocionado cuando siente que la gente lo esta escuchando y le alegra recibir aplausos. Parece bastante lógico suponer que debe existir una predisposición de todas las partes para que el momento catártico lleve al máximo nivel posible el aura de la obra. Será que “os sistemas musicais são fundamentalmente abertos, mas se fecham artificialmente quando grupos sociais concretos deles se apropiam com fins de demarcação de territorios de identidade" (Carvalho, 1999:85). Así, recuerdo un relato de Walter cuando decía:

En este caso me adapto a la situación y al lugar, porque por ahí viste...eso es un tacto que tiene el cantor, de repente vos vas a un lugar donde son todos paisanos y vos le salís cantando No saber de Ti, de Nocheros y te quedan mirando y te dicen...que linda vos pero no te aplauden porque no entienden. De repente vos le cantás Pida Patrón, de Santiago Chalar y los tipos dicen...iqque lo tiró que cantorazo!! Tenés que ganarte el aplauso. (W.M.)

A medida que me inmiscuía en lo vincular comenzaba a percibir las rispideces propias del relacionamiento característico de cualquier ámbito de interacción. Estas luchas simbólicas se manifiestan a diario entre los creadores de músicas en Fray Marcos.

Hay una parte buena y otra de celos. Hay una parte positiva y otra de celos ¿tá? Por decirte algo, acá surge un chiquilín que empezó conmigo a estudiar y cantar y todo eso y después se quiso largar como solista y después se puso en contra. Como más veterano tenés que saber sobrellevar esos temas viste, aunque por dentro también me dolía viste. Hubieron dos de esos muchachos. Después pasa el tiempo y maduran y bajan la pelota al piso...y ahora nos podemos sentar a charlar y todo eso. (W. M.). 
De lo conversado con distintas personas en Fray Marcos se puede deducir la presencia de un micro campo que, como tal, requiere (por parte de sus agentes) de una entrada al mismo. Así, Carlos Rodríguez comenta:

Yo se muy bien el ambiente ese porque conocí yo que se a Raúl Montañéz, a Carlos Molina, a Héctor Umpierrez, a Luís Alberto Martínez, a Omar Vallejo...y de ahí fui conociendo a mas gente, los que venían con ellos, otros artistas que...uno que tocaba el acordeón, el mago del acordeón que era argentino y yo que se, y te vas vinculando despacio y uno va entrando. (C.R.).

Se trata de un campo productor de agentes abanderados de elementos constitutivos de la amorfa identidad. La lógica de ese espacio social coloca a determinados sujetos en el papel de embajadores del pueblo y el músico, poeta o artista en general, viene a ocupar ese prestigioso lugar a raíz de un largo proceso interno de lucha del propio campo y de un acuerdo tácito con el resto de los habitantes del pueblo. Carlos siente que:

Ah, un cantor así... un cantor te lleva si, un cantor un poeta. Te lleva como te lleva cualquier persona, un jugador de fútbol, es un referente del pueblo, el pueblo se apoya en el...nosotros tenemos a fulano de tal.

\title{
La poesía del lugar
}

\author{
Romance a Fray Marcos \\ Hay un pueblo al este de Florida \\ hay un alma de poeta con afán \\ Y a Fray Marcos ha de cantar con alegría \\ $\mathrm{y}$ a su gente con cariño sin igual \\ El esfuerzo y el trabajo es tu consigna \\ es la lucha cotidiana por el pan \\ son obreros que se enfrentan día a día \\ defendiendo la alegría de su hogar \\ El río Santa Lucía \\ en sus barrancas marcó el destino \\ y una leyenda se abrió camino \\ de aquél matrero que en tu tierra nació \\ $Y$ te recuerdo Martín Aquino \\ como un pedazo de tradición \\ ya hace cien años que en tus orillas \\ sangre de hermanos se derramó \\ hoy te saludo pueblo querido \\ sos un pedazo de corazón \\ La plaza Artigas en el centro de tu pueblo \\ la 45 escuela del lugar \\ el homenaje al Dr. Ciro Ciambruno \\ como la calle que atraviesa la ciudad \\ Hoy la nostalgia invade mi recuerdo
}




\section{cuando invoco a Néstor Feria su cantor que tu copla recreó por la Argentina y a nuestra tierra por entero defendió (Walter Martínez)}

Esta es una canción que le dio a Walter un lugar especial en el pueblo. Cuando conversamos sobre la repercusión que tienen las composiciones de los diferentes cantores del pueblo y el mayor o menor "éxito" de las canciones Walter me dijo: Si. Tiene otro miramiento. Porque si vos haces una canción de esas que a la gente le calló bien, cuando tú pasas por la calle, pasa el cantor y...a mira...allá va fulano.

Carlos Rodríguez es un recitador muy reconocido en el pueblo. Ha ganado primeros premios en varios festivales y siempre he escuchado hablar bien de él. Se ha dedicado a recitar décimas de otros autores pero también creó las suyas propias.

\footnotetext{
Río mi Santa Lucía

Escúchame este cantar Que en tus aguas generosas

Hoy se viene a bautizar

Tienes el nombre de santa Y por ser santa mujer Cuantas veces en tu orilla Te entregué todo mi ser Cuántas quimeras soñaba Sobre tus verdes gramillas Ver que en tus aguas viajaba Don Néstor con su tropilla Blanca y negra la tropilla De Néstor tu trovador Negro el destino de Aquino Blanca María y Su amor Oh río ladrón de sueños Santa Lucia divino Que mil veces te cruzara Untando su moro Aquino Blanca y negra la tropilla De Néstor tu trovador Negro el destino de Aquino Blanca María y su amor (Carlos Rodríguez)
}

Otra creación en homenaje a Néstor Feria son los versos que le dedica Milba Perdomo quien cuenta orgullosa su recorrido por el canto.

Un pájaro azul canto Su canto aquí se escucho Era la voz del poeta Que un día sus trinos dio $\mathrm{Su}$ nido fue en esta patria

Que en esta tierra piso

Néstor Feria no te conocí Pero tus amigos hablaron de ti

La primavera te ha regalado 


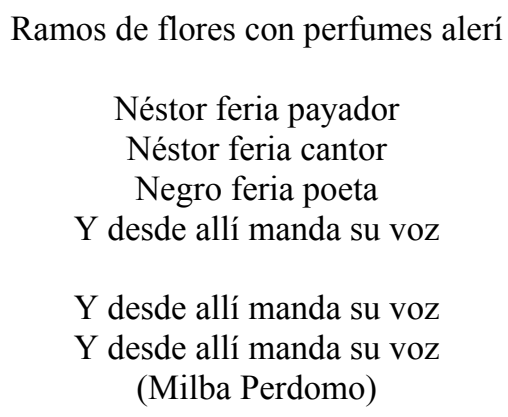

Estos son algunos ejemplos de lo que se puede encontrar en el canto de aquel lugar. Claro que estamos dejando a un lado otra serie de poesías y composiciones musicales que también forman parte del acervo musical y artístico del pueblo. En este caso se eligieron estas letras ya que dan cuenta de la presencia de los personajes a los que hemos hecho referencia en este trabajo. Esta presente en estas composiciones lo que da alguna manera forma parte de un "saludo" a aquellos que vivieron antes y generaron un camino para la tradición.

\section{Conclusiones}

En Fray Marcos me encontré con gran cantidad de cantores, decidores, payadores, poetas, recitadores y otros tantos ejemplos de personas vinculadas al canto popular, folklórico o tradicional. Tres radios comunitarias se disputan los oídos de los fraymarquinos y acompañan, con distintas programaciones, las jornadas de trabajo o descanso en el pueblo. Este panorama musical configura, como se ha desarrollado a lo largo de este trabajo, un complejo campo de tensiones y afinidades permanentes que transforman constantemente el acervo musical del pueblo y sus representaciones. Las minorías musicales se disputan un lugar en el espacio artístico de Fray Marcos. Dentro del propio género folklórico vinculado a la transmisión de un conjunto de valores relacionados a la vida rural existe una lucha por la conquista de espacios. Lo folklórico pasa a ser entonces un conjunto de prácticas, de performances, que constituyen características similares pero que da lugar a la diversidad de apropiaciones del género.

Independientemente de aspectos "técnicos" de las ejecuciones musicales propongo una mirada en función de lo performatico, o mejor dicho, del modo de presentación que encuentran ciertos músicos (Goffman, 2006) para alcanzar el efecto comunicativo deseado. Se constituye un conjunto de actores que interactúan en un campo constituido por cierta heterogeneidad performática. Lo que esta en juego es el proceso de identificación que el pueblo hace o manifiesta con sus músicos. El 
reconocimiento que obtiene el músico le da la posibilidad de construir su propio Fray Marcos, de inventar su propia tradición (Hobsbawm, 1999).

Se trata de una permanente puesta en práctica de valores o recuerdos relacionados a personalidades como Martín Aquino o Néstor Féria. Estos sujetos son constructores de un conjunto de prácticas que se llevan adelante en Fray Marcos, especialmente en relación a la producción literaria que las distintas músicas tienen. El recuerdo de las andanzas de Aquino por los campos del Uruguay, la supuesta muerte del fraile Marcos ahogado en el río, el canto de Néstor Féria, son escenas que habitan en las mentes y en el canto, en la poesía y en la inspiración de quienes pretenden continuar alimentando a ese conjunto de prácticas.

Las músicas no son únicamente el conjunto de sonidos que se ejecutan, no son solamente fenómenos físicos capaces de ser aprehendidos desde esa óptica de la ciencia generadora de tipologías reductoras a un conjunto de ecuaciones matemáticas. La música escapa, trasciende notas y escalas, géneros, ritmos y melodías. Es necesario contemplarla dentro del proceso cultural y no fuera de él. Las músicas no existen fuera de las personas que las ejecutan y escuchan. Además de sonidos, notas y escalas, existen personas y comunidades generadoras de músicas constructoras de sentidos compartidos. El músico, a demás de ejecutar notas, inspira, reúne, crea, recuerda, genera identidad.

\section{Referências}

BALANDIER, Georges. El poder en escenas. De la representación del poder al poder de la representación. Barcelona: Paidós, 1999.

BALANDIER, Georges. El desorden. Madrid: Gedisa, 1993.

BARTHES, Roland. Mitologías. México: Siglo XXI, 2005.

BOURDIEU, Pierre. ¿Qué significa hablar? Economía de los intercambios lingüísticos. Madrid: Akal, 2001.

CARVALHO, José. Transformações da sensibilidade musical contemporânea. In: Horizontes Antropológicos. Año 5. № 11. Porto Alegre: 1999. pp 59-118.

CHASTEEN, John. Héroes a caballo. Montevideo: Aguillar, 2001.

GOFFMAN, Erving. La presentación de la persona en la vida cotidiana. Bs. As: Amorrortu, 2006.

HOBSBAWM, Eric. Inventando Tradiciones. En: Hobsbawm, E, Ranger, T. The invention of tradition. Cambridge: Camb. University Press. 1999. pp 1-15.

LEVI-STRAUSS, Claude. Antropología estructural. Bs.As: Paidós, 1987.

MADFES, Irene. Martín Aquino. Discurso y tradición oral. Montevideo: UDELAR. FHCE, 1996.

MAQUEIRA, Reina. Fray Marcos. Rica historia y generoso presente. De Fray Marcos: Raices históricas. In: El Heraldo. Edición especial conmemorativa del $150^{\circ}$ aniversario de la creación del Departamento de Florida. Fascículo N 3. Director: Álvaro Riva Rey. Montevideo: El Heraldo S.A, 2006. 
NAHUM, Benjamín. Manual de historia del Uruguay. Tomo I: 1830-1903. Montevideo: EBO, 2003.

RICOEUR, Paul. Del texto a la acción. Ensayos de hermenéutica II. Bs.As: FCE, 2006. 